\title{
Where Are the Goalposts? Generational Change in the Use of Grammatical Gender in Irish
}

\author{
Siobhán Nic Fhlannchadha * and Tina M. Hickey (D) \\ School of Psychology, University College Dublin, Dublin 4, Ireland; tina.hickey@ucd.ie \\ * Correspondence: siobhan.nic-fhlannchadha@ucdconnect.ie
}

Citation: Nic Fhlannchadha, S.; Hickey, T.M. 2021. Where Are the Goalposts? Generational Change in the Use of Grammatical Gender in Irish. Languages 6: 33.

https://doi.org/10.3390/ languages6010033

Received: 24 December 2020

Accepted: 9 February 2021

Published: 22 February 2021

Publisher's Note: MDPI stays neutral with regard to jurisdictional claims in published maps and institutional affiliations.

Copyright: (c) 2021 by the authors. Licensee MDPI, Basel, Switzerland. This article is an open access article distributed under the terms and conditions of the Creative Commons Attribution (CC BY) license (https:/ / creativecommons.org/licenses/by/ $4.0 /)$.

\begin{abstract}
The Irish language is an indigenous minority language undergoing accelerated convergence with English against a backdrop of declining intergenerational transmission, universal bilingualism, and exposure to large numbers of L2 speakers. Recent studies indicate that the interaction of complex morphosyntax and variable levels of consistent input result in some aspects of Irish grammar having a long trajectory of acquisition or not being fully acquired. Indeed, for the small group of children who are L1 speakers of Irish, identifying which "end point" of this trajectory is appropriate against which to assess these children's acquisition of Irish is difficult. In this study, data were collected from 135 proficient adult speakers and 306 children (aged 6-13 years) living in Irish-speaking (Gaeltacht) communities, using specially designed measures of grammatical gender. The results show that both quality and quantity of input appear to impact on acquisition of this aspect of Irish morphosyntax: even the children acquiring Irish in homes where Irish is the dominant language showed poor performance on tests of grammatical gender marking, and the adult performance on these tests indicate that children in Irish-speaking communities are likely to be exposed to input showing significant grammatical variability in Irish gender marking. The implications of these results will be discussed in terms of language convergence, and the need for intensive support for mother-tongue speakers of Irish.
\end{abstract}

Keywords: morphosyntax; grammatical gender; bilingualism; Irish; acquisition targets

\section{Introduction}

\subsection{Interaction of Input, Experience and Formal Complexity}

Extensive cross-linguistic research has shown that successful bilingual acquisition is highly dependent on language input and experience (Montrul 2018; Unsworth 2016; Gruter and Paradis 2014; Thordardottir 2014; Gathercole and Thomas 2009; Thomas and Gathercole 2007). Gathercole and Thomas (2009) differentiated between bilinguals according to their levels of exposure to each language: they found that consistent lags between monolinguals and bilinguals in acquisition could be attributed to reduced exposure to that language on a daily basis. They argued that this shows that children need a quantitative "critical mass" of input in order to move from item-by-item learning of complex morphosyntax to system learning, particularly if they are to master the more complex aspects of grammar that are typically acquired later in monolingual acquisition. Furthermore, they proposed that the interaction of formal complexity and reduced levels of input result in some aspects of morphosyntax being susceptible to being 'timed out', i.e., show incomplete acquisition, with marking on individual items, but without evidence of typical monolingual acquisition of particular morphosyntactic systems.

Carroll (2017) criticised bilingual researchers for what she claimed to be an undue exclusive focus on exposure to explain differences in bilingual outcomes, whereas Gathercole (2017) argued that a number of studies have gone beyond language input and exposure to examine factors which interact to influence rate and success of children's bilingual language acquisition. Rodina and Westergaard (2017) noted the interaction of 
factors such as age of onset, input quantity and system transparency on the timing of acquisition of gender marking in two groups of Russian-Norwegian bilinguals in Norway. They concluded that early age of onset does not compensate for reduced levels of input in the minority language, and can impact on the acquisition of even a transparent system. Thordardottir (2014) found that 5-year-old bilinguals with equal amounts of exposure to English and French could productively use several tenses other than the present in both languages, whereas children with unequal exposure to English did not use regular or irregular English past tense accurately. Thus, there is evidence that in high-exposure contexts, bilinguals do not always diverge from monolinguals showing slow acquisition of complex systems, but that where children receive lower levels of input, this reduced exposure can interact with the relative formal complexity of specific within-language features to impact negatively on rate of acquisition of that aspect of morphosyntax in that language.

Discussion of qualitative difference in input and language experience benefits from recent considerations of the language acquisition of heritage language speakers. Montrul (2016, p. 15) included in her definition of heritage languages those "that are national minority languages: Irish in Ireland, Welsh in Wales, Basque in Spain and France, Catalan in Catalonia, Frisian in Netherlands and Germany" and defined heritage speakers as "early bilinguals of minority languages" (p. 17). Heritage speakers who are exposed to the heritage language at birth might be expected to be similar to monolingual speakers of that language, and simultaneous bilinguals ${ }^{1}$, given the emphasis on the importance of age of onset in explaining the rate, sequence and eventual success of bilingual acquisition (Unsworth 2016). However, heritage speakers' language experience, i.e., the context, quantity and quality of the input in the heritage language, and their opportunities for language use, is very different from majority language monolinguals' experience and acquisition trajectory. Montrul $(2008,2018)$ has long argued that the end of the acquisition trajectory for heritage speakers is not always successful acquisition, and that incomplete acquisition' and attrition are also possible. Some researchers (e.g., Otheguy 2016; Nance 2013) dispute the functionality of the concept of 'incomplete acquisition', arguing that speakers may have fully acquired the language to the extent that they need, or may be reflecting changes in the norms of use in input to them in the heritage language context. Montrul and Silva-Corvalán (2019) defended the term 'incomplete acquisition' as describing a phase of acquisition, whereby child heritage speakers do not use stable features of the language of adult speakers, often attributable to a major shift in exposure to majority language (such as preschool entry), leading to a decline in the critical mass needed to acquire the more complex aspects of the heritage language (Montrul and Foote 2014; Montrul and Potowski 2007). The heritage language may never be completely acquired in childhood and may stabilise in an incomplete state in adulthood, and/or experience attrition.

\subsection{Language Contact and Change in Indigenous Minority Languages}

Children's sensitivity to input factors has been found to be greater for minority languages than for majority languages (Paradis 2011). Gathercole (2014) and Gathercole and Thomas (2009) demonstrated relative ease in the acquisition of the majority language for simultaneous bilinguals, whereas they observed that acquisition of a minority language (in this case Welsh) is more vulnerable. Gathercole and Thomas (2009) argued that, for simultaneous bilinguals, majority language acquisition will be mainly unproblematic, so that, in the Welsh context, English acquisition is highly likely to happen given normal circumstance. On the other hand, they observed that minority languages are dependent on frequent and consistent input, but must contend with the fact that the sources of that input are more limited than those for the majority language, in terms of numbers of speakers and often domains of use.

1 Montrul (2008) defined simultaneous bilingualism as the acquisition of two languages following exposure to both from birth or before the age of 3 . 
Inconsistency in input to children is significant, given that they depend on recognising patterns in the input to form the perceptual and conceptual categories they need to gain productive control over their language (Lieven and Tomasello 2008). Thomas and Gathercole (2007) observed that acquisition of the opaque Welsh grammatical gender system is affected by, among other factors, the typical usage norms of proficient adults. In their study of child and adult use of Welsh grammatical gender, not one of the Welsh-dominant child participants in their study appropriately mutated vowel-initial nouns in reference to a feminine antecedent in complex distant gender constructs used to mark third-person possession. When they compared this to contemporaneous adult use of the same feature, they found that even proficient Welsh-English bilingual adults did this accurately only $14 \%$ of the time. They attributed the protracted and incomplete acquisition of the Welsh grammatical gender system to its inconsistent use by adults in input, making it vulnerable to accelerated change (Thomas and Gathercole 2007; Gathercole and Thomas 2009).

In minority language contexts, it can be a contentious issue trying to decide what constitutes the "end point" of successful acquisition, since rapid changes in adult usage gives a sense of moving goalposts. It is beyond the scope of the present paper to consider the ideological questions regarding who sets those goalposts (e.g., O'Rourke 2011; Heller and Martin-Jones 2001). Here, the aim is to examine performance data by bilingual Irish-English children and adults on a linguistic feature of Irish as it has been typically marked in traditional dialects and in the Standard language. The Standard (An Caighdeán) was based on a combination of all three traditional dialects ${ }^{2}$ when it was developed in 1958 (with ongoing revision at intervals; Rannóg an Aistriúchán 1958), and is the variety of Irish recommended for use in Government publications and textbooks and in measuring performance in written examinations. Ó Murchadha (2010) has highlighted the fact that, while there is nothing inherently superior about the Standard, it tends to be seen as the highest prestige variety by virtue of its links to formal domains such as education, the media and as part of the national standard ideology.

There is a small body of published research on the L1 acquisition of Irish among monolingual children on data collected in the early 1980s (Hickey 1990, 1991) that considered (inter alia) the link between parental input and children's earliest word order patterns in this V-initial language. Cameron-Faulkner and Hickey (2011) examined input to one child at the early stages of acquisition in an Irish-dominant household, taking a constructivist approach to linking input and output of specific structures. However, studies of data collected in recent years have recognised that most children acquiring Irish in the home are now likely to be simultaneous bilinguals, even in Irish-speaking communities, with some studies (O'Toole and Hickey 2013, 2016) charting vocabulary development in Irish and English from the earliest stages of language development. Other studies have examined the impact of English on children's Irish acquisition and use in the contemporary Gaeltacht (e.g., Péterváry et al. 2014; Lenoach 2014; Muckley 2016). Such studies have noted a drop in grammatical accuracy among school-age speakers of Irish in the Gaeltacht. Péterváry et al. (2014) examined grammatical accuracy in 50 children aged 7-11, while Lenoach (2014) also collected data from children aged 3-4 years and 15-17 years. The children in both studies were from Irish-only homes in the Connemara Gaeltacht, but the authors argued that most were in fact English dominant. Péterváry et al. (2014) used a picture description task to collect productive data and generated a 'bilingual index score' calculated by scoring children's accuracy on a range of linguistic categories (12 comparable variables [Irish-English] and 4 variables specific to Irish), including plural nouns, prepositions, and initial mutations. According to their analysis, only 19 (38\%) of the participants were balanced bilinguals, and the remaining 31 were English dominant. A limitation of this study was its dependence on identifying participants' errors and little informa-

2 Three main dialects (varieties) of Irish exist: the Connemara dialect spoken in Galway and Mayo on the west coast, the Munster/Southern dialect spoken in Kerry and Cork in the south of the country and the Ulster/Northern dialect spoken in Donegal on the north-western coast (Ó Siadhail 1989). 
tion is provided about the percentage of accurate usage of specific language features in obligatory contexts.

Lenoach (2014) observed interactions between children $(n=33)$ and their parent(s) in Gaeltacht homes and parents also kept a record of the child's interactions with others and the language of these interactions. Additional data were collected in a more controlled setting using methods such as a picture naming task and picture description task. Lenoach found that children's scores on a picture naming task were higher in English than in Irish by age 8 , noting that participants showed a higher average Irish vocabulary at age four, but their average English vocabulary was larger by 8 , and the difference was still significant at age 12. He interpreted the results as indicating incomplete acquisition in previously Irish-dominant children who experience a significant increase in exposure to English when they begin school, even in Gaeltacht areas. This was mainly attributed to interaction with peers from English-only homes, already noted by Hickey $(1999,2001,2007)$ as impacting on the Irish development and use of children from Irish-dominant homes attending naíonrai (Irish-medium preschools).

Ó Giollagáin et al. (2007) had earlier carried out a study combining data on the distribution of Irish speakers and families, and a survey of language attitudes among young people in the Gaeltacht; from these data, they concluded that the position of Irish in the Gaeltacht was severely threatened. An updated study (Ó Giollagáin and Charlton 2015) concluded that intergenerational transmission of Irish in the Gaelacht is no longer successfully producing Irish speakers, on the basis of the comparison criteria used between children's and adults language. Ó hÉallaithe (2015) criticised the methodology used, arguing that more stringent criteria for accuracy were applied to the school-age speakers' data than the adults. Following re-analysis of some of the data, Ó hÉallaithe concluded that language use among the young speakers in the Gaeltacht was stronger than Ó Giollagáin and Charlton (2015) claimed it to be. Nevertheless, these studies contributed to a sense of urgency regarding the need for educational reform in sectors catering for heritage language speakers of Irish, and contributed to the Department of Education and Skills initiating a new Policy on Gaeltacht Education 2017-2022 (Department of Education and Skills 2016) in the Gaeltacht, aiming to provide more supports for the ongoing Irish development of children from Irish-speaking homes.

While a number of recent studies of Irish acquisition have noted a drop in grammatical accuracy among younger speakers, only one other study to date has attempted to examine the use of the same feature in Irish by child and adult speakers to explore the impact of adult use of a feature on children's use. Müller et al. (2018) used a wordless story book to elicit Irish narratives from a sample of parents (19 mothers and one father) and their children aged three to six years. All of the parents were reported as being native speakers of the local dialect of Irish. They examined the accuracy and consistency in the adults' use of initial mutations in noun and verb phrases and found that low levels of adult accuracy were mirrored in their children's output, which they concluded pointed to incomplete acquisition attributable to inconsistency in input rather than to language disorder or delay in the children. An issue with using elicited or spontaneous production data of specific grammatical features as in previous studies is that comparisons across age groups can be difficult. The current study adds to this body of literature by detailed testing of aspects of a complex feature in Irish among a large sample of older child and adult speakers in Gaeltacht communities, in this instance grammatical gender marking, to consider children's performance against the backdrop of current adult usage of that feature in the wider community of speakers.

Children acquiring Irish in homes in which Irish is the dominant language tend to acquire the local dialect (see footnote 2), and exposure to the Standard is linked to school and the media. In order to situate their acquisition of Irish, Section 1.3 outlines relevant aspects of the context. 


\subsection{Irish: Rapid Sociolinguistic Changes}

Irish is the first official language of the Republic of Ireland, but despite state and constitutional support, this indigenous language remains an endangered minority language. English is the other official language of the State but continues to be the dominant language used for most official and non-official interactions. Census 2016 data (Central Statistics Office 2017) show that while 1.76 million people, or two-fifths of the population, claimed 'some' knowledge of Irish, only 73,803 (1.7\%) reported that they speak Irish daily outside the education system (interpreted as evidence that it is the language of their home). Most L1 speakers of Irish are clustered in regions known collectively as the Gaeltacht, officially designated Irish-speaking communities located mainly in geographically isolated areas on the western, southern, and northern seaboard. Most of the data for this study were collected in the Conamara Gaeltacht in the west of Ireland, where those who speak Irish daily outside of the education system are, nevertheless, in the minority.

Irish remains an obligatory subject for almost all primary and post-primary pupils, which committed to a curriculum that fosters 'both oral and written competence in Irish' (Government of Ireland 2010, p. 4). The majority of children and teenagers in Ireland learn Irish as a subject in mainstream schools, but approximately $8 \%$ of primary pupils nationally attended Irish-medium schools (Gaelscoileanna) in the 2018/19 school year (Gaelscoileanna 2019). Such widespread learning of a minority language as an L2 by speakers of a dominant language has been shown to affect the minority language. Jones (1998) found Welsh L1 children in immersion schools adopted the errors of the L2 learners rather than influencing them to use the correct forms, and similar phenomena have been noted in Ireland (e.g., O Catháin 2016; Nic Pháidín 2003). The fact that for some time, Irish L1 children have been in a minority in many classes even in Gaeltacht areas (Ó Giollagáin et al. 2007; Hickey 2001) means that heritage speakers of Irish have extensive exposure to input from L2 learners from preschool onwards in most educational settings.

Intergenerational transmission of Irish has come under growing pressure in the Gaeltacht as more parents opt to speak English in the home (Ó hIfearnáin 2008, 2013; Ó Murchadha 2019). Outside of these areas, the number of Irish L2 speakers is rising (Ó Duibhir 2018), due to a combination of Irish-medium primary and secondary schools, popular summer camps in Irish, and the statutory supports and recognition of Irish as an official working language in the EU. O'Rourke and Walsh $(2015,2020)$ examine the emergence of "new speakers" of Irish, who are individuals who acquired their language in a context other than the home, such as through immersion or other bilingual education, and who now show progress in bringing the language into new, urban spaces.

Concerns have been raised by practitioners and researchers such as $\mathrm{O}^{\prime}$ Toole and Hickey $(2013,2016)$ about the unaddressed linguistic needs of young Irish-English bilinguals, given the attenuation of Irish noted by Péterváry et al. (2014) and Ó Giollagáin et al. (2007) among primary pupils in the Gaeltacht. Parallels can be drawn with the heritage speakers of Spanish studied by Montrul and colleagues (see above) and L1 speakers of Irish whose early exposure to English means they are early Irish-English bilinguals, whose exposure to English increases further when they begin formal education and enter the classroom where, even in the Gaeltacht areas, children from homes where Irish is the dominant language have been in the minority for some time.

\subsection{Grammatical Gender as an Area of Tension between Irish and English}

Irish has an opaque system of marking grammatical gender, which uses plurifunctional markers according to complex rules. Young Irish-English bilinguals constitute an interesting group, given the significant differences in that their grammatical gender is marked in Irish but is not in English. Frenda (2011) argued that convergence with English has reinforced the linguistic structures shared by both languages, but attenuated those which they do not share, such as Irish grammatical gender marking on inanimate nouns. Montrul and Sánchez-Walker (2013) in their examination of heritage speakers' oral production of Differential Object Marking in Spanish, also found transfer from English 
(which does not mark direct objects overtly) to be an influential factor in their omission of Differential Object Marking in animate direct objects. The combination in Irish of a highly complex and opaque gender marking system that appears to require a lengthy period of exposure in order for acquisition to happen, and universal bilingualism among Irish speakers in English, appears to have accelerated the decline of gender marking in Irish among children and young adults, as will be discussed further below.

Children acquiring Irish face a significant challenge in identifying the grammatical gender of nouns: while the endings of inanimate nouns act as a clue to gender, there are many exceptions and the number of suffixes associated with either gender is high. Gender is then marked using initial mutations ${ }^{3}$, a set of morphophonological changes to the initial phoneme of words depending on the morphosyntactic context (Hickey 2012). These initial mutations are governed by definite articles and possessives (inter alia) and are applied in one of four ways: lenition, eclipsis, /t-/prefixing and/h-/prefixing. Lenition is an inflectional affix applied to the initial phoneme of a noun (see Müller et al. 2018). Orthographically, this is marked by the letter ' $h$ ' following the first consonant. Of the 13 consonants used in Irish (with palatal and velar forms), only a subset (b, c, f, g, $m$ and p) can be lenited. Lenition is a plurifunctional marker that is very widely used in Irish in a range of contexts such as to the vocative case, the genitive singular of masculine nouns, verb marking in a number of tenses, following most prefixes and some prepositions, pre-verbal particles and numerals, to mention but a few of its uses.

\subsubsection{Gender Marking Following the Definite Article}

Irish has no indefinite article, but the definite article is marked for singular (an) and plural $(n a)$. Following the article ' $a n^{\prime}$ ', the unmarked masculine noun is the default and only feminine nouns (in bold below) are lenited (underlined below):

1. a. Teach 'house' (masc.) $\rightarrow \quad$ an teach 'the house' (Det $\mathrm{N}$ masc.)

b. Máthair 'mother' (fem.) $\rightarrow \quad$ an mháthair 'the mother' (Det $\mathrm{N}$ fem.-lenited)

In the case of s-initial nouns, the masculine remains the unmarked default, while/t/prefixing is used to mark feminine s-initial noun gender:

2. a. Sionnach 'fox' (masc.) $\rightarrow \quad$ an sionnach 'the fox' (Det N masc.)

b. Srón 'nose' (fem.) $\rightarrow \quad$ an tssón 'the nose' (Det $\mathrm{N}$ fem.-/t-/prefixed)

However, for vowel-initial nouns, it is feminine nouns that are unmarked, while / $\mathrm{t}-/$ prefixing (underlined below) is applied to masculine vowel-initial nouns:

3. a. Asal 'donkey' (masc.) $\rightarrow \quad$ an $\underline{t-a s a l}$ 'the donkey' (Det $\mathrm{N}$ masc.-/ $\mathrm{t}-$ /prefixed)

b. Ubh 'egg' (fem.) $\rightarrow \quad$ an $\boldsymbol{u} b \boldsymbol{h}$ 'the egg' (Det $\mathrm{N}$ fem.)

\subsubsection{Noun Adjective Agreement}

When a consonant-initial adjective follows a singular feminine noun in the noun phrase, agreement is required, and the initial phoneme of such an adjective is subject to lenition:

4. a. Teach 'house' (masc.) + bán $\rightarrow \quad \begin{aligned} & \text { an teach bán 'the white house' } \\ & \text { (Det N (masc.) Adj) }\end{aligned}$
$\begin{aligned} & \text { b. Mhite' } \\ & \text { Máthair 'mother' (fem.) }+ \\ & \text { deas 'nice' }\end{aligned}$

Vowel-initial adjectives do not undergo any mutation.

\footnotetext{
3 Stenson (1981, p. 20): "a combination of case, gender, definiteness and number interact to determine whether or not an [initial] mutation takes place. For example, feminine nouns in the nominative singular are lenited after the definite article; they are not lenited if the definite article is absent. On the other hand, masculine nouns in the genitive singular are lenited after the definite article, but feminine genitives are not."
} 


\subsubsection{Third-Person Possession}

Third-person possession in Irish uses a gender-neutral possessive pronoun ' $a$ ' $(<a)>$ 'his $X^{\prime}$ or 'her $X^{\prime}$ ), and following this, it is the feminine that is the unmarked case, while lenition is applied to the consonant-initial possessed noun (regardless of that noun's gender) to signal masculine third-person singular possession. Lenition is applied to consonantinitial nouns (including s) possessed by masculine singular possessives:

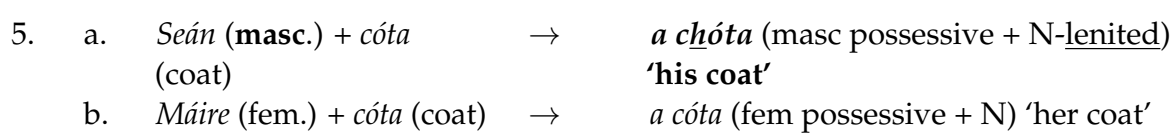

The final exceptional case is marking third-person possession on vowel-initial nouns. This is achieved through/h-/prefixing on vowel-initial nouns possessed by a feminine singular noun as antecedent, thereby reversing the pattern and making the masculine possession of such nouns the unmarked default:

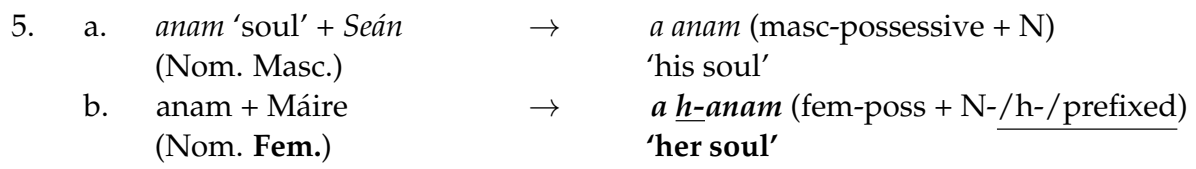

While previous studies have looked at children's spontaneous use of initial mutations to mark gender, the current study will examine these aspects of the Irish gender system in child and adult data using specially developed measures of receptive and productive grammatical gender to target specific initial mutations.

\subsection{Aims of the Research}

The first aim of this study was to assess the degree to which school-age Irish-English bilingual children (including both Irish-dominant and English-dominant speakers) mark grammatical gender accurately in their Irish production. The term 'accuracy' is used to represent the degree to which the performance data comply with the traditional and prescriptive usage of Standard Irish. The second aim was to examine how proficient adult speakers of Irish perform on these gender marking tasks. The third aim was to compare adults' and children's accuracy across language backgrounds, and the final aim was to compare performance across the age range of $6-55+$ years, as a way of examining crossgenerational change in marking grammatical gender in Irish. In addressing these aims, this paper presents data on grammatical gender test performance for Irish bilingual speakers aged 6 to 65 , and no other study of grammatical gender in Irish has undertaken such an examination of usage across the lifespan.

The results of this study will have value for researchers, policy makers, educators and parents in the Irish context and in the context of minority, indigenous and endangered languages in general. The results also amplify the findings from the field of clinical assessment, such as Müller et al. (2018) and Antonijevic-Elliott et al. (2020), who argue that it is important for Speech and Language Therapists to consider child's language experience when interpreting language performance.

\section{Sample, Measures and Methods}

\subsection{Child Participants}

The child sample comprised 306 participants, 145 males and 161 females, with an age range of $6-13(M=9.29, S D=1.413)$. All child participants were attending Irish-medium schools, having started school at approximately age four. They were recruited using a voluntary parental consent form issued to all eligible participants. All but one of the schools (an Irish-immersion school included for comparison) recruited were located in official Gaeltacht areas. Parents' occupation was used to determine children's socioeconomic status (SES), following COST Bi-SLI procedures, or, where this was not reported, the level of disadvantage of the school as identified by the Department of Education and Skills 
was used as a proxy. The child sample was evenly distributed across High, Medium and Low SES. Data about the child's home language were collected using the ChildLanguage Background Questionnaire (see Measures below) and were used to categorise child participants as being from Irish-Dominant Homes (IDHs), Bilingual Homes (BHs) or English-Dominant Homes (EDHs). Table 1 presents the distribution of the child participants according to language background categorisation and age.

Table 1. Child sample by language background and age.

\begin{tabular}{|c|c|c|c|c|c|c|c|c|}
\hline \multirow{2}{*}{$\frac{\text { Age }}{6}$} & \multicolumn{2}{|c|}{ Irish-Dominant Home IDH } & \multicolumn{2}{|c|}{ Bilingual Home BH } & \multicolumn{2}{|c|}{ English-Dominant Home EDH } & \multicolumn{2}{|c|}{ Total } \\
\hline & 1 & $0.3 \%$ & 0 & & 0 & & 1 & $0.3 \%$ \\
\hline 7 & 13 & $4 \%$ & 14 & $4.5 \%$ & 6 & $2 \%$ & 33 & $11 \%$ \\
\hline 8 & 25 & $8 \%$ & 18 & $6 \%$ & 12 & $4 \%$ & 55 & $18 \%$ \\
\hline 9 & 21 & $7 \%$ & 21 & $7 \%$ & 37 & $12 \%$ & 79 & $26 \%$ \\
\hline All 6-9 & 60 & $20 \%$ & 53 & $17.3 \%$ & 55 & $18 \%$ & 168 & $55 \%$ \\
\hline 10 & 20 & $6.5 \%$ & 19 & $6.2 \%$ & 30 & $10 \%$ & 69 & $22.5 \%$ \\
\hline 11 & 11 & $3.6 \%$ & 5 & $1.6 \%$ & 27 & $9 \%$ & 43 & $14 \%$ \\
\hline 12 & 3 & $1 \%$ & 3 & $1 \%$ & 10 & $3 \%$ & 16 & $5 \%$ \\
\hline 13 & 1 & $0.3 \%$ & 1 & $0.3 \%$ & 0 & & 2 & $0.6 \%$ \\
\hline All 10-13 & 35 & $11 \%$ & 28 & $9 \%$ & 67 & $22 \%$ & 130 & $42 \%$ \\
\hline Missing & & & & & & & 8 & $3 \%$ \\
\hline Total & 95 & $31 \%$ & 81 & $26.5 \%$ & 122 & $40 \%$ & 306 & \\
\hline
\end{tabular}

\subsection{Adult Participants}

The adult participants were 135 Irish speaker adults, a sample of the contemporaneous Irish speech community. Using the Brief-Language Background Questionnaire (see Measures below), they were categorised as one of the following: L1 speakers raised in Gaeltacht homes in which Irish was the dominant language; highly proficient L2 Speakers (HP L2); or moderately proficient L2 Speakers (MP L2). The adult participants were recruited through word of mouth and attendance by the authors in the Gaeltacht and at cultural events for Irish speakers, and were not related to the child participants described above. Forty-two of the adult participants had been raised in the Gaeltacht. Their occupation was categorised according to the International Standard Classification of Occupations and was used with level of education to estimate their socioeconomic status (SES), following Gathercole et al. (2016). Two-thirds of the participants for whom this information was reported were High SES and one-third were Medium SES. Table 2 presents the distribution of adult participants according to language background and age.

Table 2. Adult participants by language background and age.

\begin{tabular}{|c|c|c|c|c|c|c|c|c|}
\hline \multirow{2}{*}{$\begin{array}{c}\text { Age } \\
<25\end{array}$} & \multicolumn{2}{|c|}{ L1 Speakers } & \multicolumn{2}{|c|}{ Highly Proficient L2 Speaker } & \multicolumn{2}{|c|}{ Moderately Proficient L2 Speaker } & \multicolumn{2}{|c|}{ Total } \\
\hline & 9 & $6 \%$ & 10 & $8 \%$ & 21 & $15.5 \%$ & 40 & $30 \%$ \\
\hline $25-55$ & 28 & $21 \%$ & 21 & $15 \%$ & 25 & $18.5 \%$ & 74 & $55 \%$ \\
\hline $56+$ & 7 & $5 \%$ & 10 & $7 \%$ & 4 & $3 \%$ & 21 & $15 \%$ \\
\hline Total & 44 & $32 \%$ & 41 & $30 \%$ & 50 & $37 \%$ & 135 & $100 \%$ \\
\hline
\end{tabular}

\subsection{Measures}

\section{The Brief-Language Background Questionnaire (B-LBQ) (Adults)}

The B-LBQ draws on Dunn and Tree's (2009) Quick Bilingual Dominance Scale, with additional questions added to supplement the language history information. A significant feature of the B-LBQ is that participants are required to rate their proficiency in Understanding, Speaking, Writing, Reading and in Grammar in Irish. The B-LBQ is short, consisting of 13 questions. The questions map onto three factors: past, current and future language use. Cronbach's alpha was 0.830 when used with the adults in this study.

\section{The Child Language Background Questionnaire (C-LBQ)}

The C-LBQ was designed to collect detailed information about the language acquisition experience across a number of domains. Topics include demographic information, 
age of acquisition and current language use. The measure consists of 17 questions and was adapted from the Alberta Language Environment Questionnaire (Paradis et al. 2010). Cronbach's alpha was 0.921 when completed by the parents of the child participants.

\section{The Expressive Measure of Irish Morphosyntax (E-MIM)}

The Expressive Measure of Irish Morphosyntax (E-MIM) was modelled on the measure developed by Thomas and Gathercole (2007) for Welsh. The target nouns were chosen from the consonant-initial nouns which allow gender marking on the initial phoneme, and from vowel-initial nouns. Each of the selected phonemes was tested 4 times, twice with masculine and twice with feminine nouns. The nouns were equally divided between animate and inanimate nouns. Word frequency was controlled by restricting stimulus noun choice to a set of the top 1000 nouns from a corpus of the most frequent words in children's Irish language books (see Appendix A for sample items of each subtest).

E-MIM Subtest 1: Grammatical gender following the definite article (28 items)

E-MIM Subtest 2: Noun-adjective combinations (32 items)

E-MIM Subtest 3: Third-person possession (28 items)

Cronbach's alpha for E-MIM Subtests 1, 2 and 3 for the adult participants was 0.838 , 0.914 , and 0.848 respectively. When used with the children, Cronbach's alpha for E-MIM Subtests 1,2 and 3 was $0.667,0.684$, and 0.861 respectively.

\subsection{Procedure}

The Expressive Measure of Irish Morphosyntax (E-MIM) was administered by the first author to all child participants individually in a child-friendly format using an 'alien' puppet who was learning Irish. The response format was modelled through the use of sample items preceding each subtest. The child participants saw pictures of the nouns and were asked to give their responses aloud. Their responses were recorded on a digital recorder and on a scoring sheet. The E-MIM took, on average, 15 min to complete. For adult participants, they saw an example noun at the start of each task, and then saw the test nouns in written form and were asked to write their responses in an individual answer booklet. The adult participants were asked to respond as they would in normal speech.

As part of the test battery, children were also administered the Receptive Measure of Irish Morphosyntax (R-MIM; a new measure of children's ability to distinguish between referents on the basis of gender marking in different contexts), the Matrices subtest of the Weschler Abbreviated Scales of Intelligence, a standardised test of Irish reading vocabulary from $A n$ Triail Ghaeilge Dhroim Conrach do Bhunscoileanna Gaeltachta agus Lán-Ghaeilge [Drumcondra Irish Reading Vocabulary Test for Gaeltacht and Irish-medium schools], and a standardised test of English reading vocabulary from The Drumcondra Primary Reading Test-Revised. While the results of some of these measures are not presented in full in this paper, the measures were entered into some of the analyses reported below. The results for the R-MIM, the standardised test of Irish reading vocabulary, and the standardised test of English reading vocabulary are discussed in Nic Fhlannchadha and Hickey (2019). The results for the R-MIM are explored in greater detail in Nic Fhlannchadha and Hickey (2017), where the variable performance on animate and inanimate nouns is examined in more detail.

\subsubsection{Scoring}

A total score and a percentage correct score were calculated for each subtest of the E-MIM. Given that masculine consonant-initial nouns are not lenited following the definite article, nor are the adjectives that follow them, and consonant initial nouns following feminine possessor nouns are not lenited in marking possession, participants could appear to be correct on half of the items if they use a 'mark nothing' default, but have limited accuracy in actively marking grammatical gender. Consequently, a total score was calculated for nouns that require lenition, / $\mathrm{t}$-/prefixing or/h-/prefixing for each subtest. 


\subsubsection{Ethical Approval}

All measures and procedures received ethical approval from the UCD Human Sciences Research Ethics Committee. Parental consent and child assent was obtained for all child participants, and consent from all adult participants.

\section{Results}

\subsection{Irish Grammatical Gender Marking among Child Participants}

The first aim of this study was to examine the degree to which Irish-English bilingual children mark grammatical gender accurately in their Irish production. Figure 1 shows the results for the child participants of the three subtests of the Expressive Measure of Irish Morphosyntax (E-MIM) according to home language background and age for all nouns requiring active gender marking.

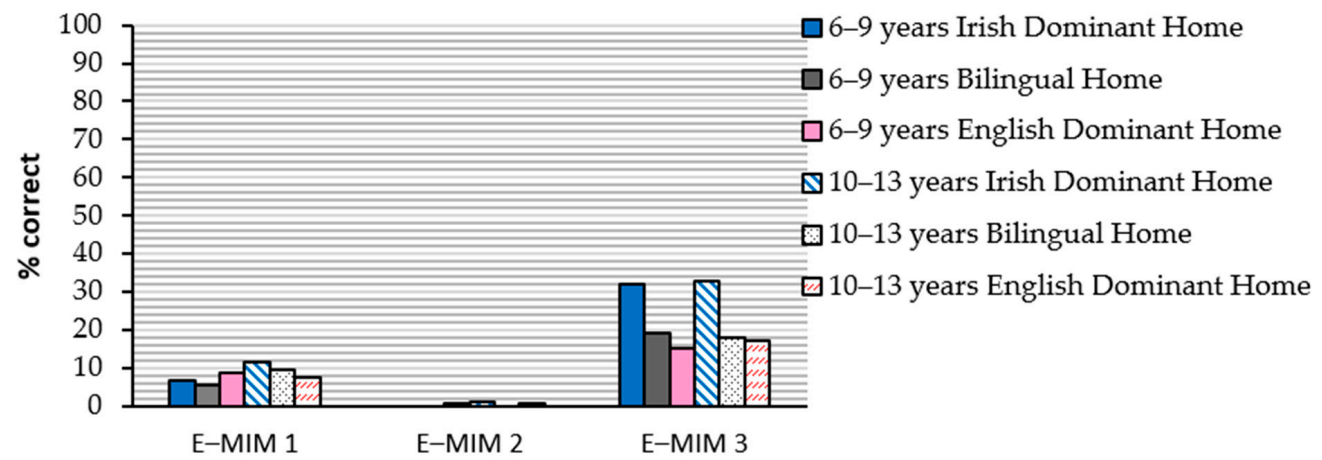

Figure 1. Percent correct scores for child participants by language background and age on the Expressive Measure of Irish Morphosyntax (E-MIM).

A floor effect was found for all child participants on E-MIM Subtest 1 and E-MIM Subtest 2 , whereby less than $10 \%$ of nouns requiring an initial mutation were actively marked for gender assignment and less than $1 \%$ of nouns were marked for noun-adjective agreement. There was considerable variability between children in the responses to E-MIM Subtest 3 (third-person possession) and these differences were explored further.

A standard multiple regression analysis was conducted to calculate how much of the variance in accuracy on E-MIM Subtest 3 was accounted for by the variables age, child language background, parental language background, Irish reading vocabulary scores, English reading vocabulary scores, school model (Gaeltacht school or immersion-school) and percentage of pupils in the school being raised in homes where Irish is the dominant language. The strength of the relationship between each of the variables was assessed using correlational analyses (see Appendix B for all results) and variables with too high or too low a correlation with the dependent variable (score on E-MIM Subtest 3) were excluded from the analysis. As the scores from E-MIM Subtest 1 and E-MIM Subtest 2 were not too highly intercorrelated with E-MIM 3 (at 0.34 and 0.24 respectively) they were included as predictor variables in this model in order to test whether accurate marking of grammatical gender assignment (Det $+\mathrm{N}$ ) and noun-adjective agreement appear to predict or be relatively independent of accuracy in marking third-person singular possession.

All the variables listed above were entered into the model, which was significant, and the total variance explained was $39.5 \%$ (adjusted $\left.R^{2}\right), F(13,184)=10.90, p<0.001$ as shown in Table 3. 
Table 3. Outcome of regression on E-MIM Subtest 3.

\begin{tabular}{|c|c|c|c|c|c|c|c|}
\hline & \multirow{2}{*}{ Unstandard. Beta } & \multirow{2}{*}{ Standard. Beta } & \multirow{2}{*}{$p$} & \multicolumn{2}{|c|}{ CI } & \multirow{2}{*}{ Part Correlation } & \multirow{2}{*}{ Tolerance } \\
\hline & & & & Lower & Upper & & \\
\hline Eng-Dom. Home & -15.64 & -0.475 & $0.001 * *$ & -22.75 & -8.54 & -0.241 & 0.256 \\
\hline Bilingual Home & -14.38 & -0.395 & $0.001^{* *}$ & -20.31 & -8.56 & -0.265 & 0.451 \\
\hline E-MIM Subtest 1 & 0.39 & 0.239 & $0.001^{* *}$ & 0.192 & 0.586 & 0.251 & 0.816 \\
\hline Age & -1.99 & -0.174 & $0.008 * *$ & -3.45 & -0.537 & -0.150 & 0.738 \\
\hline E-MIM Subtest 2 & 1.33 & 0.134 & 0.024 * & 0.178 & 2.48 & 0.126 & 0.887 \\
\hline
\end{tabular}

** when $p=0.01 ;{ }^{*}$ when $p=0.05 ; \mathrm{CI}=$ Confidence Interval; E-MIM = Expressive Measure of Irish Morphosyntax.

This analysis shows that children's language background was the strongest predictor of scores on the production test E-MIM 3 (third-person possession marking), followed by scores on E-MIM 1 (beta $=-0.239, p<0.001)$, age (beta $=-0.174, p<0.008)$ and E-MIM 2 (beta $=0.134, p<0.024)$. It should be noted that, in order to include three categories of home language background as a variable in a regression analysis, "dummy variables" must be created to allow for multiple binary comparisons between each of the language background groups. Therefore, the first line of the results presented in Table 3 above shows that the scores for child participants from EDHs were significantly lower than child participants from IDHs (alone). The second line of the results presented in Table 3 shows that the scores for child participants from BHs were also significantly lower than child participants from IDHs (alone).

\subsection{Irish Productive Grammatical Gender Marking by Adult Participants}

The second aim of this study was to examine the degree to which proficient adult speakers of Irish mark grammatical gender. A one-way between-subjects MANOVA revealed a statistically significant effect of language background, $F(6,226)=2.238, p<0.05$; Wilks' Lambda $=0.891, \eta_{\mathrm{p}}{ }^{2}=0.056$. This difference was significant for E-MIM Subtest 2 $((\mathrm{N}+\mathrm{Adj})$. Using Scheffé, mean accuracy of the highly proficient L2 participants $(M=74.82$, $S D=24.70)$ was found to be significantly greater than both the native speaker participants $(M=45.73, S D=35.67), p<0.001$, and the moderately proficient $\mathrm{L} 2$ participants $(M=50.39$, $S D=28.46), p<0.01$. While a statistically significant difference was not found on E-MIM Subtest 1 or E-MIM 3, Figure 2 demonstrates a consistent pattern of higher grammatical accuracy among the highly proficient L2 participants (HPL2) compared to the L1 (native) speakers (NAT) and the moderately proficient L2 participants (MPL2).

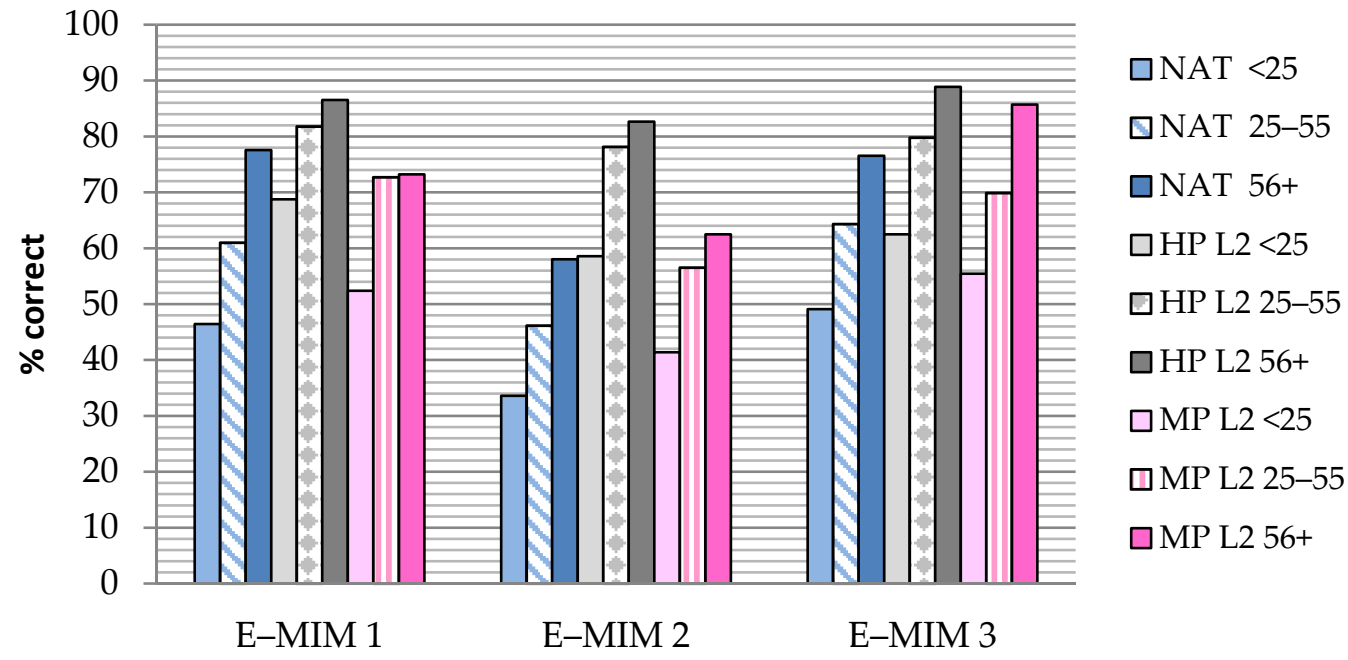

Figure 2. Percent correct scores for adult participants by language background and age on E-MIM (all subtests). 
There was also a statistically significant difference between the three adult groups by the variable of age, $F(6,226)=2.868, p<0.05$; Wilks' Lambda $=0.863, \eta_{\mathrm{p}}{ }^{2}=0.071$. Analysis of each individual dependent variable, using a Bonferroni level of 0.017 , showed that there was a significant effect for age on E-MIM Subtest $1, F(2,115)=5.887, p<0.005$, $\eta_{\mathrm{p}}{ }^{2}=0.093$, on E-MIM Subtest $2, F(2,115)=4.226, p<0.05, \eta_{\mathrm{p}}{ }^{2}=0.068$, and on E-MIM Subtest $3, F(2,115)=7.271, p<0.005, \eta_{\mathrm{p}}{ }^{2}=0.112$. Post-hoc analyses using Scheffé revealed that, in all cases, the young adult participants were significantly less accurate than both older age groups.

\subsection{Comparing the Results from the Adult and Child Participants}

The use of the same measure of grammatical gender marking by adults and children facilitated consideration of the trends in current language use among adult speakers and how they may interact with and influence children's acquisition, and of what the 'end point' of child minority language acquisition is. The child and adult performance data were compared side by side for each of the three contexts of grammatical gender use tested: following the definite article $(\operatorname{Det}+\mathrm{N})$, in noun-adjective combinations $(\mathrm{N}+\mathrm{Adj})$ and in third-person possession (third-person possession). The first comparison was of performance on Expressive Measure of Irish Morphosyntax (E-MIM) Subtest 1 (Det + N) according to language background.

While some of the adult participants across all language backgrounds did achieve over $90 \%$ accuracy on this measure, the results displayed in Figure 3 revealed that accurate use is not the norm currently. When the child and adult participants are examined side by side it is evident that the child performance does not approach adult levels, for any of the three home language background groups.

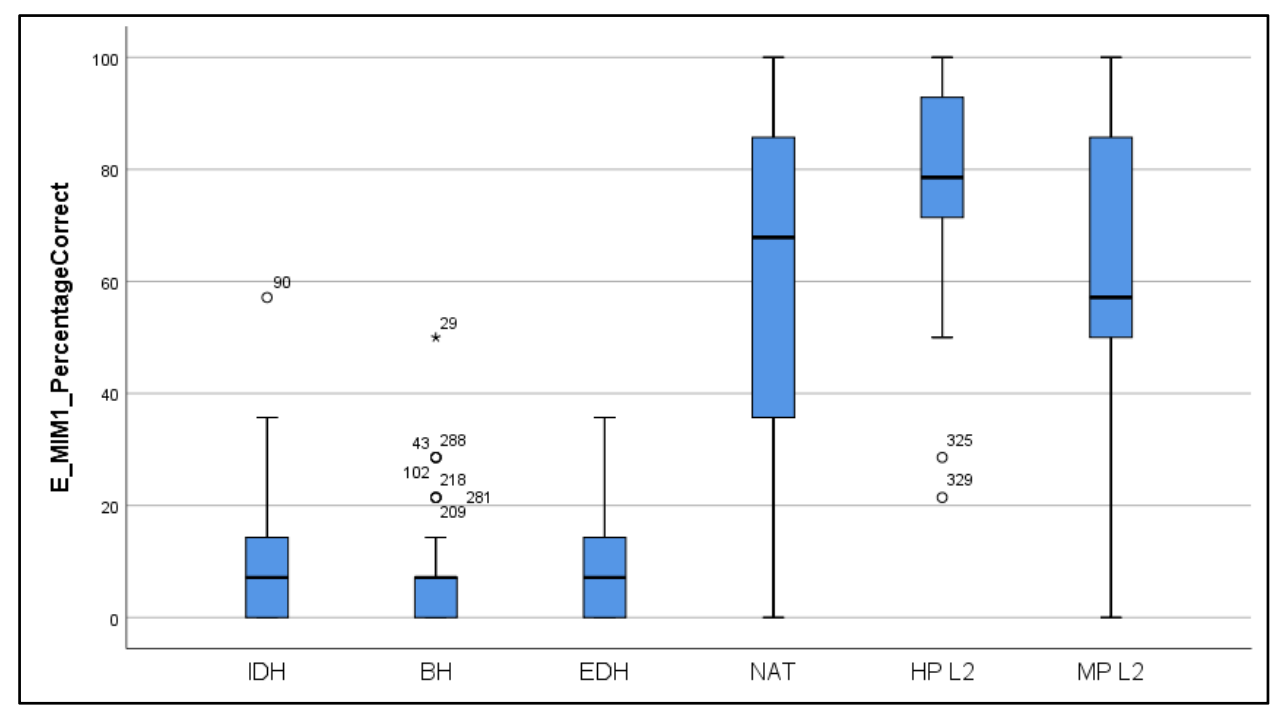

Figure 3. E-MIM Subtest $1(\operatorname{Det}+\mathrm{N})$ : Child and adult participants'accuracy by language background. $\mathrm{IDH}=$ Child, Irish-Dominant Home; $\mathrm{BH}=$ Child, Bilingual Home; EDH = Child, EnglishDominant Home; NAT = Adult L1/Native Speaker; HP L2 = Adult Highly Proficient L2 speaker; MP L2 = Adult Moderately Proficient L2 speaker. $\left({ }^{*}=\right.$ extreme value).

Examination of the adult and child performance on E-MIM Subtest 2 ( $\mathrm{N}+$ Adj agreement) revealed a similar finding (see Figure 4). All but five of the child participants were at floor level in this context of grammatical gender marking. What appeared most striking was that the children with the highest Irish input, i.e., from IDHs, showed no advantage on either of these subtests; in fact, the child participants were broadly similar in accuracy (or lack thereof) regardless of language background. This comparison points to the possibility that even the participants from IDHs do not reach the critical mass needed to acquire this feature of Irish use, despite receiving the most input in Irish of any group. 


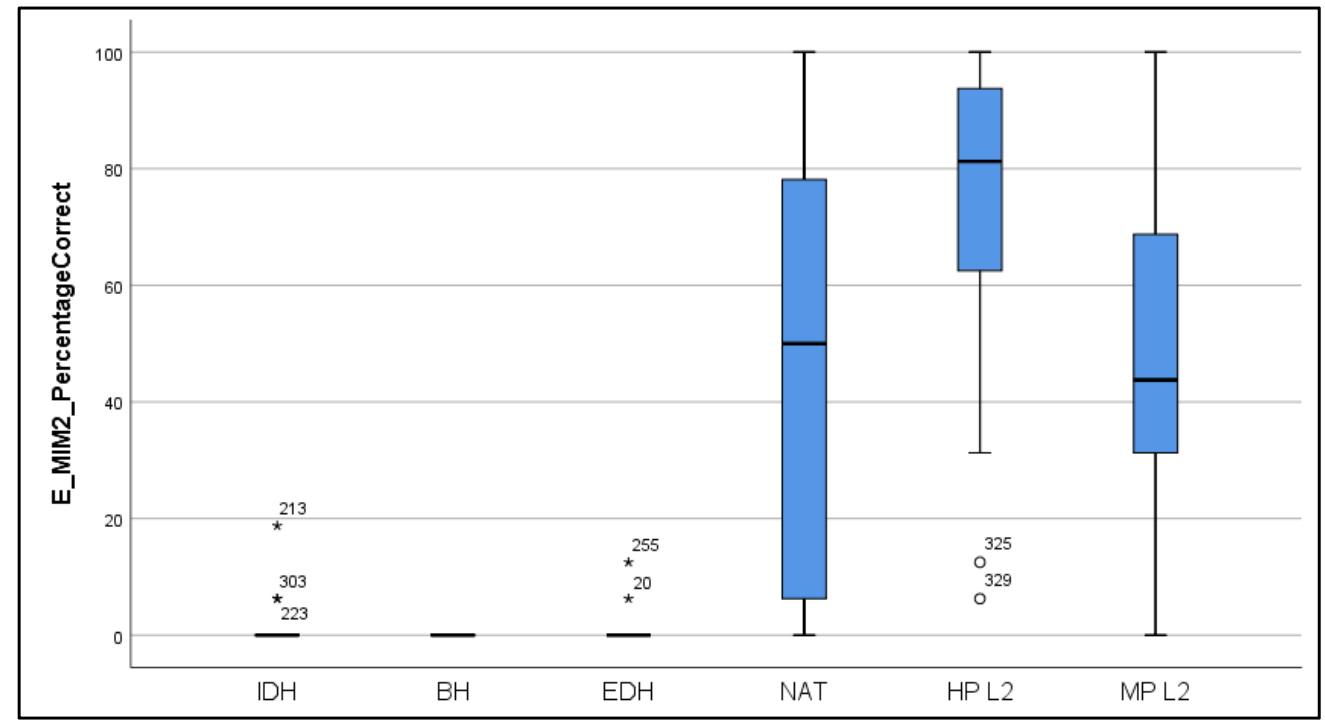

Figure 4. E-MIM Subtest $2(\mathrm{~N}+$ Adj): Child and adult participants' accuracy by language background. $\mathrm{IDH}=$ Child, Irish-Dominant Home; $\mathrm{BH}=$ Child, Bilingual Home; EDH = Child, EnglishDominant Home; NAT = Adult L1/Native Speaker; HP L2 = Adult Highly Proficient L2 speaker; MP L2 = Adult Moderately Proficient L2 speaker. $\left({ }^{*}=\right.$ extreme value).

Accuracy in marking grammatical gender in third-person possession did show a differential effect of variation in input, in that IDH children were more accurate than the others in this context, and this was mirrored by higher accuracy among adult speakers overall, as shown in Figure 5. The implications of this finding will be returned to in the Discussion.

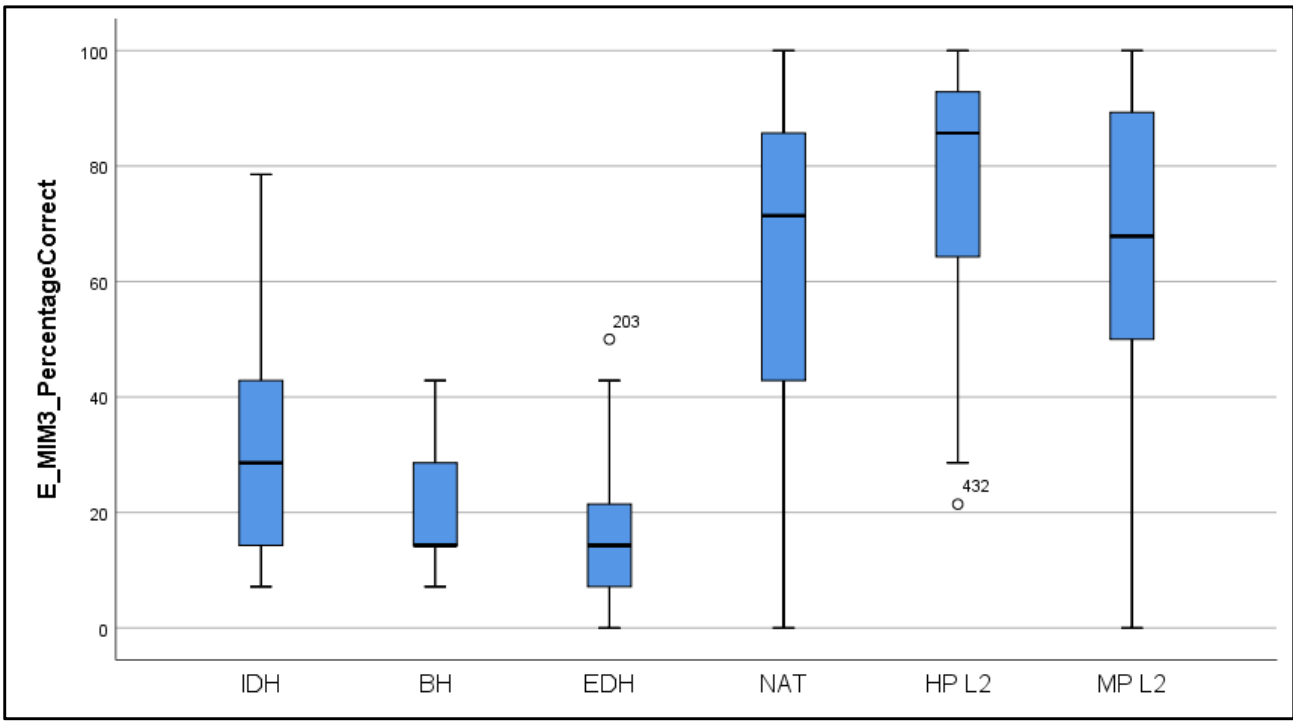

Figure 5. E-MIM Subtest 3 (third-person possession): Accuracy of child and adult participants by language background, IDH = Child, Irish-Dominant Home; $\mathrm{BH}=$ Child, Bilingual Home; $\mathrm{EDH}=$ Child, English-Dominant Home; NAT = Adult L1/Native Speaker; HP L2 = Adult Highly Proficient L2 speaker; MP L2 = Adult Moderately Proficient L2 speaker.

The final aim of this study was to examine change in the use of grammatical gender across an age range from six to over 55. The distribution of scores for the child and adult participants according to age is plotted in order to examine these generational differences. The first of these comparisons is for E-MIM Subtest 1 (Det $+\mathrm{N})$. 
Figure 6 shows a positive relationship between age and accuracy and is evidence of a generational change in the accurate use of grammatical gender on feminine nouns following the definite article. However, the relationship is not linear: there appears to be a break between the child and adult participants as the adult performance is much more accurate than child performance. The 10-13-year-old children do not show the steady increase in accuracy that would be expected if grammatical gender were being successfully acquired by ear at a later point in normal development. Figure 7 shows the distribution across the age groups for E-MIM Subtest 2.

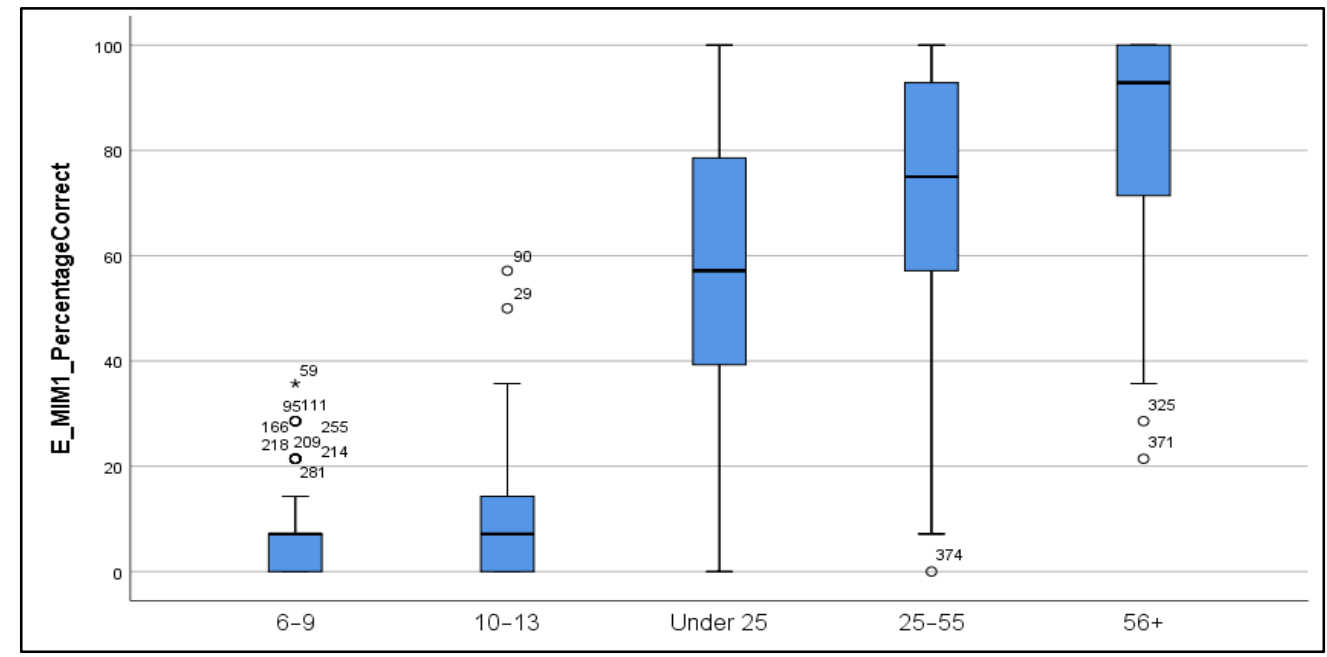

Figure 6. E-MIM Subtest $1($ Det $+\mathrm{N})$ : Accuracy of child and adult participants by age $\left({ }^{*}=\right.$ extreme value).

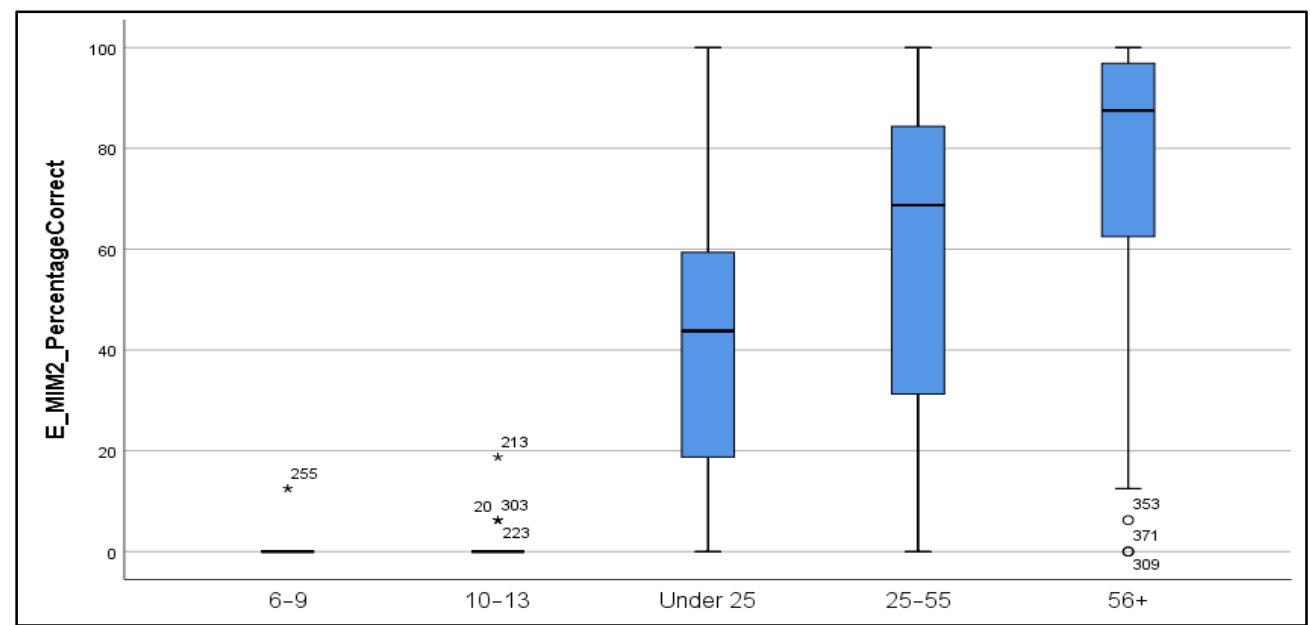

Figure 7. E-MIM Subtest $2(\mathrm{~N}+\mathrm{Adj})$ : Accuracy of child and adult participants by language background $(*$ extreme value).

Figure 7 shows that lenition on adjectives is still a feature of current usage among Irish speaker adults but is significantly more prevalent in the Irish of the oldest group. More typically, usage of lenition on adjectives is low among adults, and this, combined with inaccurate usage when it is used, is argued to have contributed to extremely low acquisition of this feature by children currently acquiring Irish.

The final comparison according to age is for E-MIM Subtest 3 (third-person possession).

Figure 8 shows that some outlying child participants were performing at the level of the median of the adults, which suggests that they are acquiring this feature before age 10, but they are in the minority. 


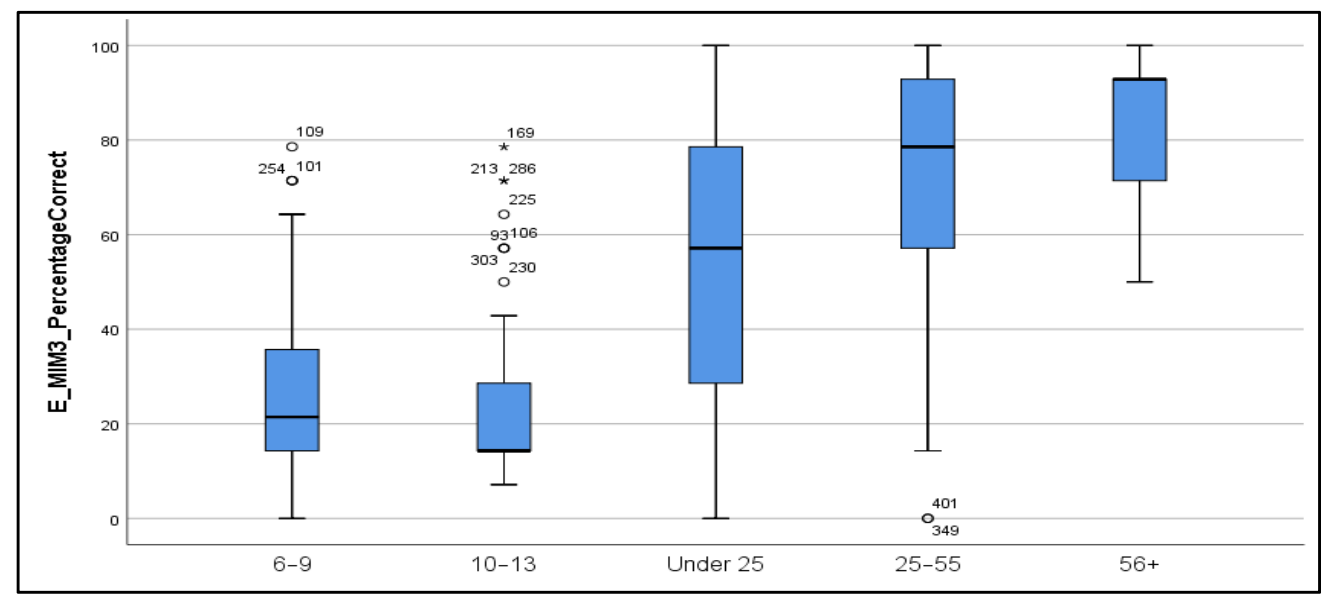

Figure 8. E-MIM Subtest 3 (third-person possession): Accuracy of child and adult participants by age $\left({ }^{*}=\right.$ extreme value $)$.

\section{Discussion}

This study examined the performance of Irish-English bilingual children and adults (encompassing a spectrum of language backgrounds) on tests of grammatical gender marking according to the Standard language. These results were considered in terms of the impact of variable use among contemporaneous adult speakers on child acquisition of this feature; such variability is argued to be all the more critical in the minority/heritage language context, given children's more limited opportunities to acquire a critical mass of input needed to construct their own language system. Cross-generational change in grammatical gender marking in Irish was also assessed in terms of its implications for our understanding of what constitutes the target, or 'end point', for successful acquisition for children acquiring Irish.

\subsection{The Impact of Input Accuracy on Child Acquisition}

A very low level of accuracy was found among the child participants for noun gender marking following the definite article and in noun-adjective combinations. Looking specifically at the latter aspect of morphosyntax, gender was hardly ever marked in this context, which is a construction lacking in English. Montrul and Sánchez-Walker (2013) found that transfer from English may have been an influential factor in the omission of Differential Object Marking in animate direct objects by heritage speakers of Spanish. Similarly, the overwhelming influence of the dominant language English is likely to be a contributing factor to the disappearance of this feature in the current usage of Irish by child L1 and L2 speakers. The results for third-person possession marking showed a higher rate of accuracy, results which correspond with the results of Müller et al. (2018) in their study of the same initial mutations using a narrative task. It is argued here that these results from the different groups of children show the impact of both quantity and quality of input on acquisition of this aspect of Irish morphosyntax.

The adult data show very variable performance on this complex feature of Irish among a sample of Irish-speaking adults representing the range of contemporaneous L1 and L2 speakers who live and work in the Gaeltacht, particularly in education. Bilingualism is overwhelmingly the norm for Irish speakers in Ireland ${ }^{4}$, and all of the participants tested were Irish-English bilinguals. The only participants who appeared to show successful acquisition of Irish grammatical gender were those aged 56 and over, regardless of their language background. The data indicate that among adults, grammatical gender marking has been least successfully acquired by the young adult native speakers. What this means for children acquiring Irish as their L1 now is that the input available to them from 'post-

4 It must be acknowledged that it is possible that some children, if cared for only by their parents in the home, may have periods of Irish dominance or even monolingualism at particular ages, provided their exposure to English media and English-speaking relatives and peers is limited. 
traditional' adult speakers (Ó Murchadha 2010), who are of an age to be the parents of young children, is likely to be very variable in terms of the grammatical accuracy of features of Irish previously marked both in the traditional dialects and in the Standard language.

These results suggest that even the participants from Irish-Dominant Homes (IDHs) do not currently reach the critical mass of consistent input needed to acquire the system of grammatical gender marking in Irish, despite receiving the most input in Irish of any group. This may reflect not just a difficulty in reaching a threshold of input with enough exemplars of this complex and opaque structure, but a more recent difficulty in reaching a critical mass of input that is consistently accurate in use of these structures. Müller et al. (2018) suggested that the younger children in their study were not on course to full acquisition of the Irish initial mutation system given that the parents in their study did not use these systems consistently in their output (see Gathercole 2007, for comparable results for Welsh). Rather than supporting Montrul and Silva-Corvalán (2019) conceptualisation of incomplete acquisition, this appears to point to rapid intergenerational change in the Irish language. The massive variability among adult speakers of Irish adds additional 'noise' to an already noisy complex system (with many exceptions and pluruifunctional markers). This level of inaccuracy greatly increases children's difficulty in identifying and extracting the generalisations they need to make in order to acquire the system productively.

Rather than system learning, both the child and adult data may be showing some evidence of item-learned marking of grammatical gender on a small number of nouns. Preliminary item-analysis showed that a limited number of feminine nouns that occur with high frequency, e.g., an fhuinneog 'the window $\mathrm{N}$-fem,' showed relatively higher levels of accuracy (see Nic Fhlannchadha 2016 for discussion). Nevertheless, while the adults' performance on this item was $87 \%$ correct overall, the children's accuracy was only $21.6 \%$, with the next most accurate feminine noun (an fhiacail 'the tooth' $\mathrm{N}$-fem) scoring only $15 \%$ in the child data. What was notable in the error analysis in the adult data was the observation that, contrary to lenition being eroded, younger adults in particular appear to overextend lenition randomly, rather than in accurate gender assignment. The youngest adult participants overextended lenition more than both other age groups, and the trend continued to the 25-55 year olds, who used overlenition more than the participants aged 56 and over. The age effect was stronger than the language background effect, in that younger native speaker adults also showed these overextension errors.

As a result, it appears that young adults and children speaking current ('post-traditional') Gaeltacht Irish are no longer acquiring a variety of the language that marks grammatical gender systematically. While some speakers may have vestigial items, remnants of the system, that are somewhat more likely to be marked, the gap between the most accurate marking of a feminine noun in the children's data and in the adult data shows that even such item-learning may be experiencing erosion.

What was noteworthy in the data was that the more transparent aspects of the system did show higher accuracy, and more grammatically accurate performance among the children with highest exposure in acquiring simpler aspects of this complex system. The more accurate performance of participants from Irish-Dominant Homes in marking third-person possession ( $a+$ lenition signalling possession by masculine antecedent) is likely to be an interaction of several critical factors: their greater exposure to Irish input, the greater salience initially of human masculine possession marking, and a higher level of adult consistency on this construction in input. This supports the findings of Antonijevic et al. (2020) in their study of Child-Directed Speech by parents of children being raised with Irish as their dominant language. They found children's use of morphosyntactic forms to be a closer approximation to accurate usage (defined as conforming with accounts of the specific regional variety of interest), when consistently and accurately produced by parents. 


\subsection{Language Environment: Change in Irish across Generations}

Péterváry et al. (2014) and Frenda (2011) argued that grammatical gender marking in noun-adjective combinations is being/has been eroded from spoken Irish. Accuracy in gender agreement has been found to be problematic for children acquiring opaque gender systems in other languages, such as Norwegian (Rodina and Westergaard 2017) and German (Montanari 2014). This erosion appears to be continuing, given the negative relationship between age and grammatical accuracy on the Expressive Measure of Irish Morphosyntax (E-MIM) Subtest 2. However, its preservation in the highly proficient L2 adult participants shows that it continues to be part of the prestige variety of the language.

The results showing a performance advantage on these tasks for highly proficient L2 speakers over native speakers point to differences in how Irish is acquired in formal versus informal contexts, and to differences in the language variety being acquired. Aspects of the Standard language that for some time appear to have ceased being marked consistently by Gaeltacht native speakers in spoken Irish are taught to L2 learners in mainstream and immersion schools and rewarded in State examinations, where L2 Irish-medium school pupils tend to out-perform Gaeltacht native speakers of Irish. The results of this study highlight the issue of mainstream schools and Irish-medium schools teaching (possibly more successfully) aspects of the Standard grammar, while Gaeltacht schools are accepting the local convergent varieties of the language, which in formal contexts such as state examinations are judged to be inaccurate (see Ó Murchadha and Flynn 2018 for further consideration in the context of teacher attitudes).

\subsection{Implications: Need for Intensive Support for Mother-Tongue Irish Speakers}

Ó hIfearnáin (2008) raised concerns that the decisions made by parents in the Gaeltacht regarding their patterns of home language use were not always made in a "fully informed climate" (p. 527). He found that some parents in the Gaeltacht attributed their decision to speak English with their children to a desire to ensure that their children 'be bilingual'. These parents were unaware that their children's acquisition of the majority language is unlikely to be threatened. Rather, the minority language requires more support and enrichment for successful acquisition to a level that will support children's academic performance in Irish-medium education and reap the cognitive benefits of bilingualism (Bialystok 2020). As noted in Section 1.2, concerns based on a body of research in the last decade showing poor outcomes in terms of Irish among school-age children in the Gaeltacht led to the development of a new Gaeltacht education policy (Department of Education and Skills 2016) which recognises the need to make appropriate provision for children being raised in Irish-speaking homes. This has led to a greater recognition of the needs of these young speakers (Ní Thuairisg and Duibhir 2019), but it is unclear whether sufficient resources and training will be available to cater for their needs in the implementation of that policy, currently being rolled out.

A necessary step therefore is to deepen and enlarge understanding of bilingualism in a minority language context among parents of heritage speakers of Irish. More systematic and specific family language supports need to be offered to Irish-speaking families from the preschool period and throughout the primary school years, in order to address these children's particular and ongoing language needs and to inform parents better with respect to the full normal trajectory of L1 acquisition of Irish alongside unavoidable exposure to the majority language English.

\subsection{Future Research}

There is an urgent need for research on the implementation and evaluation of recent policy changes in Gaeltacht education aimed at offering language enrichment and support to young speakers of Irish. Exploration of appropriate ways of empowering parents towards developing and pursuing an Irish family language plan is required in the Irish context. In particular, the connection between the home and the early years' setting needs to be reviewed to build a comprehensive community support package for families that is made 
available even before children are born. Ongoing research that includes children's voice in discussions of Family Language Planning (FLP) (Smith-Christmas and NicLeòid 2020; Smith-Christmas et al. 2019) enables children to be active participants whose reactions and attitudes shape the FLP. It would also be beneficial to include the grandparent generation in efforts to support FLP, either in their role as carers for children, or through research exploring the feasibility of involving fluent grandparents in naionrai, as has been studied in the kohanga reo in New Zealand (e.g., Mutu 2005).

Finally, there is a tendency for concerns about endangered languages to lead to a focus on oral language skills, and this can obscure the importance of promoting literacy in the language, since literacy is a vital part of promoting enrichment. Stenson and Hickey (2016) explored why teachers urgently need more appropriate pre- and in-service education in how to teach Irish orthography, as well as education regarding the benefits of building authentic literacy activities into heritage language learning for all learners. The classroom is a structured language learning context for children, in that the language input can be shaped in ways that support or enhance the salience of the more complex features such as grammatical gender, in a context in which children expect to be challenged and to engage in formal learning. Concurrently, efforts at increasing domains of meaningful use should also focus on promoting Irish use with peers, through activities such as youth clubs, the arts and sport, thereby giving the language life, relevance, and value outside of the educational context.

\section{Conclusions}

Grammatical gender marking following the definite article and in noun-adjective combinations appear no longer to be reliably marked in the variety of Irish spoken in Irishspeaking communities by child speakers, as well as adult speakers under the age of 55 . Third-person possession appears to differ, as both the child and adult participants showed greater accuracy on this than in the other contexts. The advantage of child participants from Irish-Dominant Homes on this construction is attributed to its salience and greater likelihood of accuracy in input: children are likely to arrive at a mass of exemplars earlier when adult input contains more consistently accurate use of this feature. However, it is evident from the significant gap between the oldest children and the youngest adults that the acquisition trajectory between these two points is not steady. The intervening period is when the majority attend second-level schools, a period when both oral and written accuracy according to the Standard language is rewarded in second-level state examinations. In this regard, it is noteworthy that some young adults who identified as native speakers in Nic Fhlannchadha and Hickey (2018) reported concern regarding the rewards for grammatical accuracy in state examinations, noting that they felt disadvantaged by their Gaeltacht schools giving them less formal teaching in Irish grammar than they perceived to be the practice in Irish-medium immersion schools. It appears that until recent reforms of Gaeltacht education policy, the formal teaching of Standard Irish grammar may have been accorded lower priority in Gaeltacht schools than in schools catering for L2 learners. Ongoing reforms seek to build on research pointing to more effective methods of teaching Irish grammar in Gaeltacht and Irish-medium schools (e.g., Ní Dhiorbháin 2014; Ó Duibhir 2011, 2018).

The results of this study point to children with higher levels of Irish exposure showing accuracy levels that are relatively more advanced than their peers from Bilingual Homes or English-Dominant Homes, but their acquisition of grammatical gender is still ongoing at the end of primary school, and is therefore at high risk of being 'timed out.' A key issue arising from this study concerns the evaluation of children's acquisition of a minority language in a context in which the language they are hearing around them is showing high levels of variability and change. The 'end point' towards which children's acquisition is progressing, or indeed the 'goalposts' at which they are aiming, is in a state of flux. Müller et al. (2018) have questioned this comparison of child language use to a standard or target variety of a minority language in clinical assessment, and Otheguy (2016) and 
Pires and Rothman (2009) have raised related criticisms in other contexts. Greater clarity is needed about which factors contribute significantly to children's acquisition of Irish morphosyntax, and which end points are judged appropriate in assessing them currently. Measures being used to assess the language success of these bilingual children need to take their language experience into consideration, including the specific complex components of the language which may require a longer acquisition trajectory, and the dynamics of majority and minority language interaction.

Author Contributions: Conceptualization, T.M.H. and S.N.F.; methodology, T.M.H. and S.N.F.; software, S.N.F.; validation, T.M.H. and S.N.F.; formal analysis, S.N.F.; investigation, S.N.F.; resources, T.M.H. and S.N.F.; data curation, S.N.F.; writing—original draft preparation, S.N.F.; writing—review and editing, S.N.F. and T.M.H.; visualization, T.M.H. and S.N.F.; supervision, T.M.H.; project administration, S.N.F.; funding acquisition, T.M.H. Both authors have read and agreed to the published version of the manuscript.

Funding: This research was funded by An Chomhairle um Oideachas Gaeltachta agus Gaelscolaíochta (COGG) as a PhD bursary (2011-2015).

Institutional Review Board Statement: The study was conducted according to the guidelines of the Declaration of Helsinki, and approved by the Institutional Ethics Review Committee of UCD Human Subjects' Research Ethics (protocol codes HS-13-44, HS-14-16, HS-14-17, approved on 17 Oct 2013, and 18 March 2014 respectively).

Informed Consent Statement: Informed consent was obtained from all adult participants involved in the study. Parents' consent was obtained for their children's participation, in addition to children's assent.

Data Availability Statement: Enquiries regarding the data presented in this study to the first author. Data not publicly available in compliance with commitments to participants in ethics process.

Conflicts of Interest: The authors declare no conflict of interest.

\section{Appendix A. E-MIM Practice Items Subtests 1-3}

\section{Subtest 1 Practice items}

Participant is shown a picture of a bed.

Researcher says: "Chonaic Marcas an leaba." [Marcas saw the bed.]

Researcher says: "Céard faoin gceann seo?" [What about this one?]

Participant is shown a picture of a hand.

Participant says: "Chonaic Marcas an lámh." [Marcas saw the hand.]

Subtest 2 Practice items

Participant is shown a picture of a grey cat.

Researcher says: "Chonaic Marcas an cat liath." [Marcas saw the grey cat.]

Researcher says: "Céard faoin gceann seo?" [What about this one?]

Participant is shown a picture of an orange lamp.

Participant says: "Chonaic Marcas an lampa oráiste." [Marcas saw the orange lamp.]

Subtest 3 Practice items

Participant is shown a picture of a girl and a stuffed toy.

Researcher says: Dearfaidh mise "Áine agus teidi" agus is féidir leat "is maith liom a teidi", nó "ní maith liom a teidí" a rá." [I'll say 'this is Áine', and you can say 'I like her teddy' or 'I don't like her teddy'.]

Researcher says: "Céard faoin gceann seo? Tógálaí agus teach." [What about this one? Builder and house.]

Participant is shown a picture of a builder holding a model house.

Participant says: "Seo tógálaí, is maith liom a theach." [This is a builder, I like his house.] 


\section{Appendix B}

Table A1. Intercorrelations between study variables.

\begin{tabular}{|c|c|c|c|c|c|c|c|c|c|c|c|c|c|c|c|c|c|}
\hline & 1 & 2 & 3 & 4 & 5 & 6 & 7 & 8 & 9 & 10 & 11 & 12 & 13 & 14 & 15 & 16 & 17 \\
\hline \multicolumn{18}{|l|}{ 1. Child Background } \\
\hline 2. Parent Background & $0.74 * *$ & & & & & & & & & & & & & & & & \\
\hline 3. Teacher Background & 0.03 & 0.08 & & & & & & & & & & & & & & & \\
\hline 4. Age & $-0.23 * *$ & $-0.20 * *$ & 0.04 & & & & & & & & & & & & & & \\
\hline 5. SES & -0.09 & -0.03 & -0.11 & $-0.14 *$ & & & & & & & & & & & & & \\
\hline $\begin{array}{l}\text { 6. \% Irish-Dominant pupils } \\
\text { in School }\end{array}$ & $0.62 * *$ & $0.63^{* *}$ & 0.04 & $-0.33^{* *}$ & $0.23 * *$ & & & & & & & & & & & & \\
\hline 7. School Model & $0.44 * *$ & $0.47 * *$ & $0.54 * *$ & -0.22 ** & -0.11 & $0.63 * *$ & & & & & & & & & & & \\
\hline 8. Non-Verbal IQ & -0.11 & $-0.15 *$ & 0.01 & $0.28 * *$ & $-0.16^{* *}$ & $-0.29 * *$ & -0.08 & & & & & & & & & & \\
\hline 9. Irish Vocab & $0.31 * *$ & $0.21^{* *}$ & $0.17^{* *}$ & -0.1 & $-0.18 * *$ & $0.19 * *$ & $0.30^{* *}$ & 0.20 ** & & & & & & & & & \\
\hline 10. English Vocab & -0.08 & -0.09 & -0.04 & $-0.14 *$ & $0.29 * *$ & $-0.12 *$ & $-0.12 *$ & 0.30 ** & $0.47 * *$ & & & & & & & & \\
\hline 11. R-MIM 1 & 0.03 & -0.04 & -0.07 & 0.05 & 0.04 & 0.00 & -0.03 & $0.13 *$ & 0.08 & 0.07 & & & & & & & \\
\hline 12. R-MIM 2 & 0.05 & 0.03 & -0.11 & 0.05 & -0.06 & 0.01 & 0.02 & 0.01 & 0.05 & -0.04 & 0.06 & & & & & & \\
\hline 13. R-MIM 3 & 0.05 & 0.01 & 0.09 & $0.27 * *$ & $0.12 *$ & -0.01 & 0.09 & $0.20^{* *}$ & $0.29 * *$ & $0.15 *$ & 0.03 & -0.06 & & & & & \\
\hline 14. R-MIM 4 & $0.13 *$ & 0.09 & 0.00 & -0.05 & -0.01 & $0.23 * *$ & $0.22 * *$ & 0.00 & 0.11 & -0.04 & 0.10 & 0.11 & 0.06 & & & & \\
\hline 15. R-MIM 5 & 0.16 ** & 0.14 * & 0.03 & -0.034 & -0.04 & 0.04 & 0.06 & 0.00 & 0.07 & 0.00 & 0.06 & $0.15 *$ & -0.05 & -0.03 & & & \\
\hline 16. E-MIM 1 & 0.03 & -0.01 & 0.08 & 0.09 & 0.01 & -0.04 & 0.02 & 0.11 & $0.16^{*}$ & 0.17 * & 0.06 & -0.04 & $0.24^{* *}$ & -0.08 & 0.09 & & \\
\hline 17. E-MIM 2 & 0.03 & -0.01 & 0.07 & -0.03 & -0.07 & 0.08 & 0.01 & 0.01 & -0.01 & 0.01 & 0.03 & 0.06 & 0.00 & 0.06 & 0.10 & $0.28^{* *}$ & \\
\hline 18. E-MIM 3 & $0.44 * *$ & $0.35^{* *}$ & -0.06 & $-0.20^{* *}$ & 0.06 & $0.3^{* *}$ & 0.15 * & -0.07 & $0.3^{* *}$ & $0.19 * *$ & 0.05 & 0.00 & $0.18 * *$ & 0.01 & 0.13 & 0.34 ** & $0.24 * *$ \\
\hline
\end{tabular}




\section{References}

Antonijevic, Stanislava, Sarah-Ann Muckley, and Nicole Müller. 2020. The role of consistency in use of morphosyntactic forms in child-directed speech in the acquisition of Irish, a minority language undergoing rapid language change. Journal of Child Language 47: 267-88. [CrossRef]

Antonijevic-Elliott, Stanislava, Rena Lyons, Mary Pat O' Malley, Natalia Meir, Ewa Haman, Natalia Banasik, Clare Carroll, Ruth McMenamin, Margaret Rodden, and Yvonne Fitzmaurice Lyons. 2020. Language assessment of monolingual and multilingual children using non-word and sentence repetition tasks. Clinical Linguistics \& Phonetics 34: 293-311.

Bialystok, Ellen. 2020. Bilingual effects on cognition in children. In Oxford Research Encyclopedia of Education. Oxford: Oxford University Press, Available online: https:/ / oxfordre.com/education/view/10.1093/acrefore/9780190264093.001.0001/acrefore-97801902 64093-e-962 (accessed on 1 December 2020).

Cameron-Faulkner, Thea, and Tina M. Hickey. 2011. Form and function in Irish child directed speech. Cognitive Linguistics 22: 569-94. [CrossRef]

Carroll, Susanne E. 2017. Exposure and input in bilingual development. Bilingualism: Language and Cognition 20: 37-41. [CrossRef]

Central Statistics Office. 2017. Census 2016. The Irish Language. Available online: http://www.cso.ie/en/media/csoie/ releasespublications/documents / population/2017/7_The_Irish_language.pdf (accessed on 1 December 2020).

Department of Education and Skills. 2016. Policy on Gaeltacht Education 2017-2022. Available online: https://www.gov.ie/en/ publication/5cfd73-policy-on-Gaeltacht-education-2017-2022/ (accessed on 1 February 2021).

Dunn, Alexandra L., and Jean E. Fox Tree. 2009. A quick, gradient Bilingual Dominance Scale. Bilingualism: Language E Cognition 12: 273-89.

Frenda, Alessio S. 2011. Gender in Irish between continuity and change. Folia Linguistica 45: 283-316. [CrossRef]

Gaelscoileanna. 2019. Statistics. Online Document. Available online: https://gaeloideachas.ie/i-am-a-researcher/statistics/ (accessed on 2 December 2020).

Gathercole, Virginia C. Mueller. 2007. Miami and North Wales, so far and yet so near: A constructivist account of morphosyntactic development in bilingual children. International Journal of Bilingual Education E Bilingualism 10: $224-47$.

Gathercole, Virginia C. Mueller. 2014. Bilingualism matters: One size does not fit all. International Journal of Behavioural Development 38: 359-66. [CrossRef]

Gathercole, Virginia C. Mueller. 2017. Straw man: Who thought exposure was the ONLY factor? Bilingualism: Language and Cognition 20: 23-24. [CrossRef]

Gathercole, Virginia C. Mueller, and Enlli Môn Thomas. 2009. Bilingual first-language development: Dominant language takeover, threatened minority language take-up. Bilingualism: Language E Cognition 12: 213-37.

Gathercole, Virginia C. Mueller, Ivan Kennedy, and Enlli Môn Thomas. 2016. Socioeconomic level \& bilinguals' performance on language \& cognitive measures. Bilingualism: Language \& Cognition 19: 1057-78.

Government of Ireland. 2010. 20 Year Strategy for the Irish Language 2010-2030. Available online: http:/ /www.ahg.gov.ie/app/ uploads/2015/07/20-Year-Strategy-English-version.pdf (accessed on 1 December 2020).

Gruter, Theres, and Johanne Paradis. 2014. Input E Experience in Bilingual Development. Amsterdam: John Benjamins Publishing Company.

Heller, Monica, and Marilyn Martin-Jones. 2001. Voices of Authority: Education \& Linguistic Difference. Westport: Ablex Publishing.

Hickey, Tina M. 1990. The acquisition of Irish: A study of word order development. Journal of Child Language 17: 17-41. [CrossRef] [PubMed]

Hickey, Tina M. 1991. Mean length of utterance \& the acquisition of Irish. Journal of Child Language 18: 553-69. [PubMed]

Hickey, Tina M. 1999. Parents \& early immersion: Reciprocity between home \& immersion preschool. The International Journal of Bilingual Education \& Bilingualism 2: 94-113.

Hickey, Tina M. 2001. Mixing beginners \& native speakers in Irish immersion: Who is immersing whom? Canadian Modern Language Review 57: 443-74.

Hickey, Tina M. 2007. Children's language networks in minority language immersion: What goes in man not come out. Language $\mathcal{E}$ Education 21: 46-65.

Hickey, Tina M. 2012. ILARSP: A grammatical profile of Irish. In The Languages of LARSP. Edited by Martin J. Ball, David Crystal and Paul Fletcher. Clevedon: Multilingual Matters, pp. 149-66.

Jones, M. C. 1998. Language Obsolescence and Revitalization: Linguistic Change in Two Sociolinguistically Contrasting Welsh Communities. Oxford: Oxord University Press.

Lenoach, Ciarán. 2014. Sealbhú Neamhiomlán na Gaeilge mar Chéad Teanga sa Dátheangachas Dealaitheach [Incomplete Acquisition of Irish as a First Language in Subtractive Bilingualism]. Doctoral Dissertation, Ollscoil na hÉireann, Gaillimh, Ireland.

Lieven, Elena, and Michael Tomasello. 2008. Children's first language acquisition from a usage-based perspective. In Handbook of Cognitive Linguistics and Second Language Acquisition. Edited by Peter Robinson and Nick C. Ellis. London: Routledge, pp. 168-96.

Montanari, Elke. 2014. Grammatical gender in the discourse of multilingual children's acquisition of German. Linguistik Online 64: 57-68. 
Montrul, Silvina. 2008. Incomplete Acquisition in Bilingualism: Re-Examining the Age Factor. Amsterdam: John Benjamins Publishing Company.

Montrul, Silvina. 2016. The Acquisition of Heritage Languages. Cambridge: Cambridge University Press.

Montrul, Silvina. 2018. Heritage language development: Connecting the dots. International Journal of Bilingualism 22: 530-46. [CrossRef]

Montrul, Silvina, and Carmen Silva-Corvalán. 2019. The social context contributes to the incomplete acquisition of aspects of heritage languages. Studies in Second Language Acquisition 41: 269-73. [CrossRef]

Montrul, Silvina, and Kim Potowski. 2007. Command of gender agreement in school-age Spanish-English bilingual children. International Journal of Bilingualism 11: 301-28. [CrossRef]

Montrul, Silvina, and Noelia Sánchez-Walker. 2013. Differential object marking in child and adult Spanish heritage speakers. Language Acquisition 20: 109-32. [CrossRef]

Montrul, Silvina, and Rebecca Foote. 2014. Age of acquisition interactions in bilingual lexical access: A study of the weaker language of L2 learners \& heritage speakers. International Journal of Bilingualism 18: 274-303.

Muckley, Sarah-Ann. 2016. Language Assessment of Native Irish Speaking Children: Towards Developing Diagnostic Testing for Speech and Language Therapy Practice. Doctoral Dissertation, National University of Ireland, Galway, Ireland.

Müller, Nicole, Sarah-Ann Muckley, and Stanislava Antonijevic-Elliott. 2018. Where phonology meets morphology in the context of rapid language change and universal bilingualism: Irish initial mutations in child language. Clinical Linguistics and Phonetics 33: 3-19. [CrossRef]

Mutu, Margaret. 2005. In search of the missing Māori links: Maintaining both ethnic identity and linguistic integrity in the revitalization of the Māori language. International Journal of the Sociology of Language 172: 117-32. [CrossRef]

Nance, Claire. 2013. Phonetic Variation, Sound Change, \& Identity in Scottish Gaelic. Doctoral Dissertation, University of Glasgow, Glasgow, UK.

Nic Fhlannchadha, Siobhán. 2016. Investigating the later stages of Irish acquisition [Iniúchadh ar shealbhú níos déanaí na Gaeilge]. Doctoral Dissertation, University College Dublin, Dublin, Ireland.

Nic Fhlannchadha, Siobhán, and Tina M. Hickey. 2017. Acquiring an opaque gender system in Irish, an endangered indigenous language. First Language 37: 475-99. [CrossRef]

Nic Fhlannchadha, Siobhán, and Tina M. Hickey. 2018. Minority language ownership and authority: Perspectives of native speakers and new speakers. International Journal of Bilingual Education and Bilingualism 21: 38-53. [CrossRef]

Nic Fhlannchadha, Siobhán, and Tina M. Hickey. 2019. Assessing children's proficiency in a minority language: Exploring the relationships between home language exposure, test performance and teacher and parent ratings of school-age Irish-English bilinguals. Language and Education 33: 340-62. [CrossRef]

Ní Dhiorbháin, Aisling. 2014. Bain Súp As! Treoir nua Maidir le Múineadh na Gramadai [Give It a Go! A New Direction in the Teaching of Grammar]. Dublin: COGG.

Ní Thuairisg, Laoise, and Pádraig Ó Duibhir. 2019. Teacht in Inmhe. Baile Átha Cliath: Lárionad Taighde DCU um Fhoghlaim agus Teagasc na Gaeilge.

Nic Pháidín, Caoilfhionn. 2003. Cén fáth nach?'-Ó chanúint go críól. In Idir Lúibíní. Edited by Róisín Ní Mhianáin. Dublin: Cois Life, pp. 113-30.

Ó Catháin, Brian. 2016. The Irish language in present-day Ireland. In Sociolinguistics in Ireland. Edited by Raymond Hickey. London: Palgrave, pp. 41-59.

Ó Duibhir, Pádraig. 2011. "I thought that we had good Irish": Irish immersion students' insights into their target language use. In Immersion Education: Practices, Policies, Possibilities. Edited by Diana J. Tedick, Donna Christian and Tara W. Fortune. Bristol: Multilingual Matters, pp. 145-65.

Ó Duibhir, Pádraig. 2018. Immersion Education: Lessons from a Minority Language Context. Bristol: Multilingual Matters.

Ó Giollagáin, Conchúr, and Martin Charlton. 2015. Nuashonrú ar an Staidéar Cuimsitheach Teangeolaíoch ar Úsáid na Gaeilge sa Ghaeltacht 2006-2011. [Update on the Comprehensive Linguistic Study on the Use of Irish in the Gaeltacht]. Maynooth: NUI Maynooth.

Ó Giollagáin, Conchúr, Seosamh Mac Donnacha, Fiona Ní Chualáin, Aoife Ní Shéaghdha, and Mary O’Brien. 2007. Comprehensive Linguistic Study of the Use of Irish in the Gaeltacht: Complete Report. Report Prepared for the Department of Arts, Heritage and the Gaeltacht by Acadamh na hOllscolaíochta Gaeilge, NUIG, with Institiúid Náisiúnta um Anailís Réigiúnach agus Spásúil. Maynooth: NUI Maynooth.

Ó hÉallaithe, Donncha. 2015. Anailís: Níl scéal na Gaeltachta chomh duairc is a Tuairiscítear sa Nuashonrú. [Analysis: The Story of the Gaeltacht Is Not as Grim as Is Reported in the New Report] Tuairisc. June 12. Available online: http://tuairisc.ie/anailis-nilsceal-na-Gaeltachta-chomh-duairc-is-a-tuairiscitear-sa-nuashonru-o-heallaithe/ (accessed on 2 February 2021).

Ó hIfearnáin, Tadhg. 2008. Raising children to be bilingual in the Gaeltacht: Language preference \& practise. International Journal of Bilingual Education E Bilingualism 10: 510-28.

Ó hIfearnáin, Tadhg. 2013. Family language policy, first language Irish speaker attitudes and community-based response to language shift. Journal of Multilingual and Multicultural Development 34: 348-65. [CrossRef]

Ó Murchadha, Noel. 2010. Standard, standardisation \& assessments of standardness in Irish. Proceedings of the Harvard Celtic Colloquium 30: 207-35.

Ó Murchadha, Noel. 2019. Is Furasta locht a Fháil ar Ghaeilgeoirí a Labhraíonn Béarla lena Bpáistí, ach ceist Chasta í [It Is Easy to Find Fault with Irish Speakers Who Speak English to Their Children, but It Is a Complex Issue] Tuairisc. January 29. Available online: 
https:/ / tuairisc.ie/is-furasta-locht-a-fhail-ar-ghaeilgeoiri-a-labhraionn-bearla-lena-bpaisti-ach-ceist-chasta-i/ (accessed on 3 December 2020).

Ó Murchadha, Noel, and Colin J. Flynn. 2018. Educators' target language varieties for language learners: Orientation toward 'native' and 'nonnative' norms in a minority language context. The Modern Language Journal 102: 797-813. [CrossRef]

Ó Siadhail, Mícheál. 1989. Modern Irish: Grammatical Structure E Dialectal Variation. Cambridge: Cambridge University Press.

O'Rourke, Bernadette. 2011. Whose language is it? Struggles for language ownership in an Irish language classroom. Journal of Language, Identity \& Education 10: 327-45.

O'Rourke, Bernadette, and John Walsh. 2015. New speakers of Irish: Shifting boundaries across time and space. International Journal of the Sociology of Language 231: 63-83. [CrossRef]

O'Rourke, Bernadette, and John Walsh. 2020. New Speakers of Irish in the Global Context: New Revival? Abingdon: Routledge.

O'Toole, Ciara, and Tina M. Hickey. 2013. Diagnosing language impairment in bilinguals: Professional experience \& perception. Child Language Teaching \& Therapy 29: 91-109.

O'Toole, Ciara, and Tina M. Hickey. 2016. Bilingual language acquisition in a minority context: Using the Irish-English Communicative Development Inventory to track acquisition of an endangered language. International Journal of Bilingual Education and Bilingualism 20: 146-62. [CrossRef]

Otheguy, Ricardo. 2016. The linguistic competence of second-generation bilinguals: A critique of 'incomplete acquisition'. Romance Linguistics 2013: Selected Papers from the 43rd Linguistic Symposium on Romance Languages (LSRL).

Paradis, Johanne. 2011. The impact of input factors on bilingual development: Quantity versus quality. Linguistic Approaches to Bilingualism 1: 67-70. [CrossRef]

Paradis, Johanne, Kristyn Emmerzael, and Tamara Sorenson Duncan. 2010. Assessment of English language learners: Using parent report on first language development. Journal of Communication Disorders 43: 474-97. [CrossRef]

Péterváry, Tamás, Brian Ó Curnáin, Conchúr Ó Giollagáin, and Jerome Sheahan. 2014. Analysis of Bilingual Competence: Language Acquisition among Young People in the Gaeltacht. Dublin: An Chomhairle um Oideachas Gaeltachta agus Gaelscolaíochta.

Pires, Acrisio, and Jason Rothman. 2009. Disentangling sources of incomplete acquisition: An explanation for competence divergence across heritage grammars. International Journal of Bilingualism 13: 211-38. [CrossRef]

Rannóg an Aistriúchán. 1958. Gramadach na Gaeilge agus litriú na Gaeilge: An caighdeán oifigiúil [The Grammar and Spelling of Irish: The Official Standard] 1958. Dublin: Government of Ireland.

Rodina, Yulia, and Marit Westergaard. 2017. Grammatical gender in bilingual Norwegian-Russian acquisition: The role of input and transparency. Bilingualism: Language and Cognition 20: 197-214. [CrossRef]

Smith-Christmas, Cassie, and Síleas L. NicLeòid. 2020. How to turn the tide: The policy implications emergent from comparing a 'post-vernacular FLP' to a 'pro-Gaelic FLP'. Language Policy 19: 575-93. [CrossRef]

Smith-Christmas, Cassie, Mari Bergroth, and Irem Bezcioğlu-Göktolga. 2019. A kind of success story: Family language policy in three different sociopolitical contexts. International Multilingual Research Journal 13: 88-101. [CrossRef]

Stenson, Nancy. 1981. Studies in Irish Syntax. Tubingen: Gunter Narr, vol. 8.

Stenson, Nancy, and Tina M. Hickey. 2016. When regular is not easy: Cracking the code of Irish orthography. Writing Systems Research 8: 187-217. [CrossRef]

Thomas, Enlli Mon, and Virginia C. Mueller Gathercole. 2007. Children's productive command of grammatical gender \& mutation in Welsh: An alternative to rule-based learning. First Language 27: 251-78.

Thordardottir, Elin. 2014. The typical development of simultaneous bilinguals. In Input E Experience in Bilingual Development. Amsterdam: John Benjamins Publishing Company, pp. 141-60.

Unsworth, Sharon. 2016. Quantity and quality of language input in bilingual language development. In Bilingualism across the Lifespan: Factors Moderating Language Proficiency. Edited by Elena Nicoladis and Simona Montanari. Washington, DC: American Psychological Association, pp. 103-21. 